\title{
Adsorptive removal of arsenic from water by an iron-zirconium binary oxide adsorbent
}

\author{
Zongming Ren ${ }^{\mathrm{a}}$, Gaosheng Zhang ${ }^{\mathrm{a}, *}$, J. Paul Chen ${ }^{\mathrm{b}}$

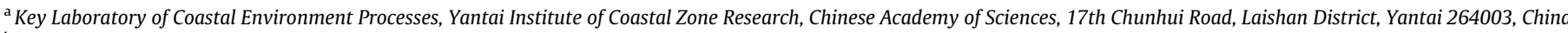 \\ ${ }^{\mathrm{b}}$ Divison of Environmental Science and Engineering, National University of Singapore, 1 Engineering Drive 2, E1A-02-19, Singapore 117576, Singapore
}

\section{A R T I C L E I N F O}

\section{Article history:}

Received 9 September 2010

Accepted 5 January 2011

Available online 21 January 2011

\section{Keywords:}

Fe-Zr binary oxide

Arsenate

Arsenite

Adsorption

Removal

\begin{abstract}
A B S T R A C T
Arsenate and arsenite may exist simultaneously in groundwater and have led to a greater risk to human health. In this study, an iron-zirconium $(\mathrm{Fe}-\mathrm{Zr}$ ) binary oxide adsorbent for both arsenate and arsenite removal was prepared by a coprecipitation method. The adsorbent was amorphous with a specific surface area of $339 \mathrm{~m}^{2} / \mathrm{g}$. It was effective for both $\mathrm{As}(\mathrm{V})$ and $\mathrm{As}(\mathrm{III})$ removal; the maximum adsorption capacities were 46.1 and $120.0 \mathrm{mg} / \mathrm{g}$ at $\mathrm{pH}$ 7.0, respectively, much higher than for many reported adsorbents. Both $\mathrm{As}(\mathrm{V})$ and $\mathrm{As}(\mathrm{III})$ adsorption occurred rapidly and achieved equilibrium within $25 \mathrm{~h}$, which were well fitted by the pseudo-second-order equation. Competitive anions hindered the sorption according to the sequence $\mathrm{PO}_{4}^{3-}>\mathrm{SiO}_{3}^{2-}>\mathrm{CO}_{3}^{2-}>\mathrm{SO}_{4}^{2-}$. The ionic strength effect experiment, measurement of zeta potential, and FTIR study indicate that $\mathrm{As}(\mathrm{V})$ forms inner-sphere surface complexes, while $\mathrm{As}(\mathrm{III})$ forms both inner- and outer-sphere surface complexes at the water/Fe-Zr binary oxide interface. The high uptake capability and good stability of the Fe-Zr binary oxide make it a potentially attractive adsorbent for the removal of both $\mathrm{As}(\mathrm{V})$ and $\mathrm{As}(\mathrm{III})$ from water.
\end{abstract}

(c) 2011 Elsevier Inc. All rights reserved.

\section{Introduction}

Arsenic is ubiquitous in the environment and of worldwide serious concern due to its high toxicity and carcinogenicity. Long-term drinking water exposure causes cancer of the liver, lung, kidney, bladder, and skin as well as skin thickening (hyperkeratosis), neurological disorders, muscular weakness, and loss of appetite and nausea [1-3]. To minimize these health risks, a strict guideline limit of $10 \mathrm{ppb}(10 \mu \mathrm{g} / \mathrm{L})$ provided by the World Health Organization (WHO) [4] has been adopted as the drinking water standard by many countries.

In natural waters, arsenic occurs predominantly in inorganic form as arsenate and arsenite, referred to as $\mathrm{As}(\mathrm{V})$ and $\mathrm{As}(\mathrm{III})$. $\mathrm{As}(\mathrm{III})$ is much more toxic [5], soluble, and mobile than $\mathrm{As}(\mathrm{V})$. A variety of treatment processes such as coagulation/precipitation $[6,7]$, ion-exchange [8], adsorption $[4,9,10]$, and membrane processes $[8,11]$ have been employed to remove arsenic. Adsorption methods are considered to be the most promising technologies because the system can be simple to operate and cost-effective [10]. However, most adsorbents, both natural and synthetic materials, are effective for $\mathrm{As}(\mathrm{V})[12,13]$, but fail in the case of $\mathrm{As}(\mathrm{III})$ $[14,15]$. To achieve higher arsenic removal, pretreatment for As(III) oxidation is therefore usually involved, followed by sorp-

\footnotetext{
* Corresponding author. Fax: +86 05352109000.

E-mail address: gszhang@yic.ac.cn (G. Zhang).
}

tion of the $\mathrm{As}(\mathrm{V})$ formed onto metal oxyhydroxides. But the pretreatment results not only in higher run cost but also in more complex operation. Therefore, there is urgent demand for economical, effective, and reliable adsorbents that are capable of removing both $\mathrm{As}(\mathrm{V})$ and $\mathrm{As}(\mathrm{III})$ simultaneously from contaminated drinking water.

Among a variety of available sorbents for arsenic removal, iron (hydr)oxides, including amorphous hydrous ferric oxide, poorly crystalline hydrous ferric oxide (ferrihydrite), goethite, and akaganéite $[12,16,17]$, are well-known for their high affinity toward arsenic, low cost, and environmental friendliness. Recently, the development of composite adsorbents containing iron oxide has gained considerable attention [18-20], since they have advantages over these components. For examples, an Fe-Ce bimetal oxide adsorbent synthesized by Zhang et al. [18] exhibited a much higher $\mathrm{As}(\mathrm{V})$ adsorption capacity than individual $\mathrm{Ce}$ and Fe oxides is prepared by the same procedure. A novel Fe-Mn binary oxide adsorbent developed by Zhang et al. [19] demonstrated enhanced arsenite removal through oxidization and then adsorption. Gupta and Ghosh [20] reported the synthesis and use of Fe-Ti binary mixed oxide for arsenic sorption.

Hydrous zirconium oxide, with high resistance to attacks by acids, alkalis, oxidants, and reductants, is more suitable for the adsorption of arsenite than iron oxide [21]. Therefore, it can be anticipated that an $\mathrm{Fe}-\mathrm{Zr}$ binary oxide would simultaneously be able to remove both arsenate and arsenite effectively. 
However, few studies are available in the literature on arsenic removal by $\mathrm{Fe}-\mathrm{Zr}$ binary oxides. Gupta et al. demonstrated that a nanostructure iron(III)-zirconium(IV) binary mixed oxide with an $\mathrm{Fe} / \mathrm{Zr}$ molar ratio of 9:1 was much more effective for arsenite than arsenate removal [22,23]. However, the maximum adsorption capacity for arsenate was only $9.36 \mathrm{mg} / \mathrm{g}$. In addition, the synthetic route involved a process of heating, which was not favorable for large-scale production of sorbent. It is therefore necessary to develop new synthetic routes by which Fe-Zr binary oxide could be synthesized under milder conditions and be effective for both arsenate and arsenite removal.

In this study, a simple coprecipitation method was established to prepare an innovative Fe-Zr binary oxide adsorbent at ambient temperature. The main objectives of this research were (1) to characterize the prepared $\mathrm{Fe}-\mathrm{Zr}$ binary oxide by a variety of techniques; (2) to evaluate its arsenic adsorption capacities and examine the influence of solution $\mathrm{pH}$, ionic strength, and coexisting ions on arsenic adsorption; and finally; (3) to explain the adsorption mechanisms for both arsenate and arsenite.

\section{Materials and methods}

\subsection{Materials}

All chemicals are analytical grade and used without further purification. Reaction vessels (glass) were cleaned with $1 \% \mathrm{HNO}_{3}$ and rinsed several times with deionized water before use. As(III) and $\mathrm{As}(\mathrm{V})$ stock solutions were prepared with deionized water using $\mathrm{NaAsO}_{2}$ and $\mathrm{NaHAsO}_{4} \cdot 7 \mathrm{H}_{2} \mathrm{O}$, respectively. Arsenic working solutions were freshly prepared by diluting arsenic solutions with deionized water.

\subsection{Preparation of $\mathrm{Fe}-\mathrm{Zr}$ binary oxide}

The Fe-Zr binary oxide was prepared according to the following procedure: Ferric chloride hexahydrate $\left(\mathrm{FeCl}_{3} \cdot 6 \mathrm{H}_{2} \mathrm{O}, 0.05 \mathrm{~mol}\right)$ and zirconyl chloride octahydrate $\left(\mathrm{ZrOCl}_{2} \cdot 8 \mathrm{H}_{2} \mathrm{O}, 0.0125 \mathrm{~mol}\right)$ were dissolved in $400 \mathrm{ml}$ deionized water. Under vigorous magnetic stirring, sodium hydroxide solution $(2 \mathrm{~mol} / \mathrm{L})$ was added dropwise to raise the solution $\mathrm{pH}$ to around 7.5. After addition, the suspension formed was continuously stirred for $1 \mathrm{~h}$, aged at room temperature for $4 \mathrm{~h}$, and then washed several times with deionized water. The suspension was then filtrated and dried at $65^{\circ} \mathrm{C}$ for $4 \mathrm{~h}$. The dry material was crushed and stored in a desiccator for use. The obtained material appeared in the form of a fine powder.

\subsection{Adsorbent characterization}

X-ray diffraction (XRD) analysis was carried out on a D/Max-3A diffractometer (Rigaku Co., Japan) using Ni-filtered copper $\mathrm{K}_{1}$ radiation. The specific surface area was measured by nitrogen adsorption using the BET method with a Micromeritics ASAP 2000 surface area analyzer (Micromeritics Co., USA). The particle size of the adsorbent was determined by a Mastersizer 2000 (Malvern Co., UK). The particle shapes were observed using a Hitachi S3500N (Hitachi Co., Japan) scanning electron microscope (SEM).

A zeta potential analyzer (Zetasizer 2000, Malvern Co., UK) was used to analyze the zeta potentials of $\mathrm{Fe}-\mathrm{Zr}$ binary oxide particles before and after arsenic adsorption. The content of the Fe-Zr binary oxide in the solution was about $200 \mathrm{mg} / \mathrm{L}$ and the initial arsenic concentration was $10 \mathrm{mg} / \mathrm{L}$. $\mathrm{NaNO}_{3}$ was used as a background electrolyte to maintain an approximately constant ionic strength of $0.01 \mathrm{M}$. After being mixed for $72 \mathrm{~h}$ to ensure the achievement of adsorption equilibrium, $20 \mathrm{ml}$ of oxide suspension was transferred to a sample tube. The zeta potential of the suspension was then measured by electrokinetic analysis.

FTIR spectra were collected on a Nicolet 5700 FTIR spectrophotometer (Nicolet Co., USA) using a transmission model. Samples for FTIR determination were ground with spectral grade $\mathrm{KBr}$ in an agate mortar. IR spectra of arsenate adsorbed onto Fe-Zr binary oxide were obtained as dry samples in $\mathrm{KBr}$ pellets corresponding to $5 \mathrm{mg}$ of sample in approximately $200 \mathrm{mg}$ of spectral grade $\mathrm{KBr}$. All IR measurements were carried out at room temperature.

X-ray photoelectron spectra (XPS) were collected on an ESCALab-220i-XL spectrometer with a monochromatic Al Ka X-ray source $(1486.6 \mathrm{eV})$. C1s peaks were used as an inner standard calibration peak at $284.7 \mathrm{eV}$. For wide-scan spectra, an energy range of $0-1100 \mathrm{eV}$ was used with pass energy $80 \mathrm{eV}$ and step size $1 \mathrm{eV}$. The high-resolution scans were conducted according to the peak being examined with pass energy $40 \mathrm{eV}$ and step size $0.05 \mathrm{eV}$. The XPS results were collected in binding energy forms and fitted using a nonlinear least-squares curve-fitting program (XPSPEAK41 Software).

\subsection{Batch adsorption tests}

\subsubsection{Adsorption kinetics}

The rate of arsenic adsorption is an important factor in arsenic removal. The kinetics experiments were carried out at room temperature $\left(25 \pm 1{ }^{\circ} \mathrm{C}\right)$. A defined amount of arsenic stock solution was added in a 1000-ml glass vessel. Then, a corresponding amount of deionized water was added to make $750 \mathrm{ml}$ of 5,10 , $20 \mathrm{mg} / \mathrm{L}$ arsenic solution. The ionic strength was maintained at $0.01 \mathrm{M}$ by adding $0.638 \mathrm{~g}$ sodium nitrate. After the solution $\mathrm{pH}$ was adjusted to $7.0 \pm 0.1$ by adding $0.1 \mathrm{M} \mathrm{HCl}$ and/or $\mathrm{NaOH}$, $0.15 \mathrm{~g}$ of Fe-Zr binary oxide was added to obtain a $0.2 \mathrm{~g} / \mathrm{L}$ suspension. The suspension was mixed with a magnetic stirrer at an agitation speed of $140 \mathrm{rpm}$, and the $\mathrm{pH}$ was maintained at $7.0 \pm 0.1$ throughout the experiment by addition of dilute acid and/or base solutions. Approximately 5-ml aliquots were taken from the vessel at predetermined times. The samples were immediately filtered through a $0.45-\mu \mathrm{m}$ membrane filter. The concentrations of arsenic in the filtered solutions were determined using inductively coupled plasma atomic emission spectroscopy (ICP-AES).

\subsubsection{Effect of $p H$ and ionic strength}

To investigate the influence of $\mathrm{pH}$ and ionic strength on the arsenic adsorption, experiments were carried out by adding $10 \mathrm{mg}$ of the adsorbent sample into $150-\mathrm{ml}$ glass vessels, containing $50 \mathrm{ml}$ of $10 \mathrm{mg} / \mathrm{L}$ arsenic solution. The ionic strength of the solutions was varied from $0.001 \mathrm{M}$ to $0.1 \mathrm{M}$ by adding $\mathrm{NaNO}_{3}$. The $\mathrm{pH}$ of the solutions was adjusted every $4 \mathrm{~h}$ with dilute $\mathrm{HNO}_{3}$ or/and $\mathrm{NaOH}$ solution to designated values in the range 3-12 during the shaking process. The equilibrium $\mathrm{pH}$ was measured and the supernatant was filtered through a $0.45-\mu \mathrm{m}$ membrane after the solutions were mixed for $36 \mathrm{~h}$. Then the residual arsenic concentration in the supernatant solutions was determined. Additionally, to evaluate the leaching of Fe and $\mathrm{Zr}$ from the adsorbent at different $\mathrm{pHs}$, the Fe and $\mathrm{Zr}$ concentrations in the supernatant solutions were also measured using ICP-AES.

\subsubsection{Adsorption isotherms}

The arsenic adsorption isotherm was determined using batch tests at the initial $\mathrm{pH}$ values of $7.0 \pm 0.1$. Initial arsenic concentration was varied from 5 to $40 \mathrm{mg} / \mathrm{L}$. In each test, $10 \mathrm{mg}$ of the adsorbent sample was loaded in the $150-\mathrm{ml}$ glass vessel and $50 \mathrm{ml}$ of solution containing different amounts of arsenic was then added to the vessel. Ionic strength of the solution was adjusted to $0.01 \mathrm{M}$ with $\mathrm{NaNO}_{3}$. The vessels were shaken on an orbit shaker at $140 \mathrm{rpm}$ for $36 \mathrm{~h}$ at $25 \pm 1{ }^{\circ} \mathrm{C}$. After the reaction period, all 
samples were filtered by a $0.45-\mu \mathrm{m}$ membrane filter and analyzed for arsenic. The quantity of adsorbed arsenic was calculated by the difference of the initial and residual amounts of arsenic in solution divided by the weight of the adsorbent.

\subsubsection{Effect of coexisting ions}

The influence of common coexisting anions in water such as sulfate, bicarbonate, silicate, and phosphate on the removal of arsenic was investigated by adding sodium sulfate, sodium bicarbonate, sodium silicate, and sodium phosphate to $10 \mathrm{mg} / \mathrm{L}$ of arsenic solution. In addition, the effect of calcium and magnesium ions on arsenic adsorption was also studied by adding lime nitrate and magnesium nitrate into arsenic solution. The solution $\mathrm{pH}$ was adjusted to $7.0 \pm 0.1$. A defined amount $(10 \mathrm{mg})$ of $\mathrm{Fe}-\mathrm{Zr}$ binary oxide was added and the solutions were agitated at $140 \mathrm{rpm}$ for $36 \mathrm{~h}$ at $25 \pm 1^{\circ} \mathrm{C}$. After filtration by a 0.45 - $\mu \mathrm{m}$ membrane filter, the residual concentration of arsenic was analyzed using ICP-AES.

\subsection{Analytical methods}

Arsenic concentration was determined using ICP-AES (Optima 2100 DV, Perkin Elmer Co., USA). Prior to analysis, the aqueous samples were acidified with concentrated $\mathrm{HCl}$ in an amount of $1 \%$ and stored in acid-washed glass vessels. All samples were analyzed within $24 \mathrm{~h}$ of collection.

\section{Results and discussion}

\subsection{Characterization of prepared Fe-Zr binary oxide}

The powder X-ray diffraction pattern of the synthesized Fe-Zr binary oxide is illustrated in Fig. 1. It shows two broad peaks at approximately $35.2^{\circ}$ and $61.2^{\circ}$, consistent with $d$ spacing of 0.254 and $0.150 \mathrm{~nm}$, respectively, which are similar to those of the poorly ordered two-line ferrihydrite $[24,25]$. This indicates that the prepared oxide is amorphous and similar to two-line ferrihydrite.

The morphology of the Fe-Zr binary oxide was examined by a scanning electron microscope. Fig. 2 shows that the adsorbent particles are aggregated with many nanoparticles, leading to a rough surface and a porous structure. The distribution of particle size of the powdered adsorbent is shown in Fig. S1 (Supplementary materials), indicating that the main particle size of this binary oxide is in the range $2-30 \mu \mathrm{m}$. BET analysis shows that the sorbent has a specific surface area of $339 \mathrm{~m}^{2} / \mathrm{g}$ with a pore volume of $0.21 \mathrm{~cm}^{3} / \mathrm{g}$. The pore size distribution of this sorbent is shown in Fig. S2. The sorbent presented a wide pore size range from 50 to below $1.5 \mathrm{~nm}$.

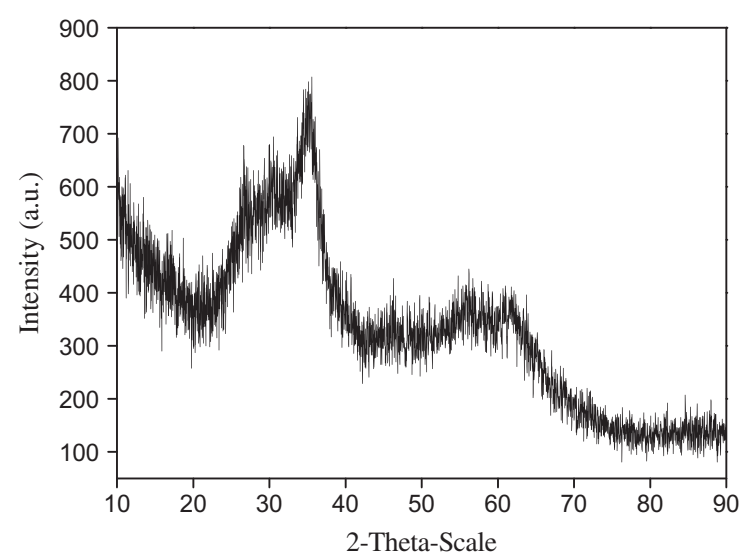

Fig. 1. XRD diffraction pattern of Fe-Zr binary oxide with a Fe/Zr molar ratio of 4:1.

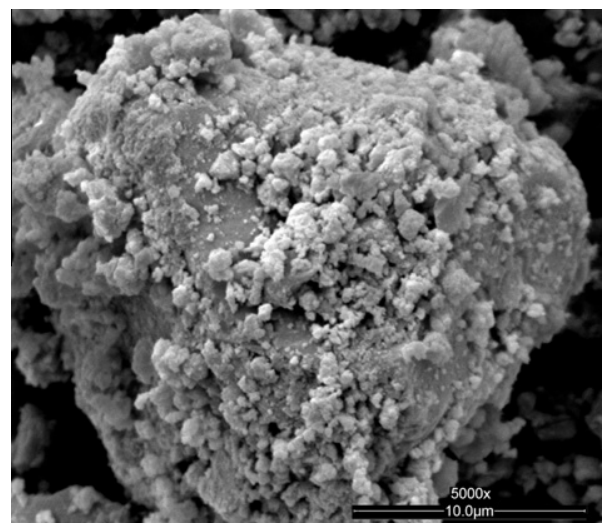

Fig. 2. SEM micrograph $(\times 5000)$ of Fe-Zr binary oxide particles.

The concentrations of dissolved $\mathrm{Fe}$ and $\mathrm{Zr}$ under different $\mathrm{pH}$ are shown in Fig. S3. The Fe concentrations are all below $0.06 \mathrm{mg} / \mathrm{L}^{1}$ and the $\mathrm{Zr}$ concentrations all below $0.01 \mathrm{mg} / \mathrm{L}^{1}$ in the tested $\mathrm{pH}$ range, which are far below the limit of drinking water standard [26]. Very limited metal leakage would not cause metal contamination in the environment, indicating the good stability of this adsorbent.

\subsection{Adsorption kinetics}

The adsorption kinetics of arsenic on Fe-Zr binary oxide at various initial concentrations was investigated in this study. Fig. 3 shows the change of adsorbed arsenic as a function of contact time. It is obvious that the adsorption process can be divided into two steps. In the first rapid step, over $80 \%$ of the equilibrium adsorption capacity is achieved within $4 \mathrm{~h}$. In the following step, intraparticle diffusion dominates and the adsorption slows down. The time taken to reach equilibrium is about $25 \mathrm{~h}$. Therefore, for all other batch experiments, the contact time was maintained as $36 \mathrm{~h}$, higher than the equilibrium time of $25 \mathrm{~h}$, to ensure complete adsorption. Adsorption due solely to electrostatic processes is usually very rapid, on the order of seconds [17]. The adsorption of arsenic by the Fe-Zr binary oxide is on the order of hours, which may indicate specific adsorption occurring between the arsenic species and the surface of the adsorbent.

Kinetic data analysis for arsenic sorption onto the Fe-Zr binary oxide was studied with a pseudo-first-order model [27] and a pseudo-second-order model [28]. The mathematical representations of the models are given in

$\ln \left(q_{e}-q_{t}\right)=\ln q_{e}-k_{1} t$

$\frac{t}{q_{t}}=\frac{1}{k_{2} q_{e}^{2}}+\frac{t}{q_{e}}$

where $q_{e}$ and $q_{t}$ are the adsorption capacities (mg/g) of the adsorbent at equilibrium and at any time $t(\mathrm{~h})$, respectively; and $k_{1}$ $\left(\mathrm{h}^{-1}\right)$ and $k_{2}(\mathrm{~g} \mathrm{mg} / \mathrm{h})$ are the related adsorption rate constants.

The rate constants obtained from pseudo-first-order and pseudo-second-order models are summarized in Table 1. For both arsenate and arsenite, the experimental data fitted the pseudo-second-order model better than the pseudo-first-order model. This indicates that the adsorption process might be chemisorption. The rate constant of the pseudo-second-order equation decreases with increasing initial arsenic concentration, indicating that arsenic adsorption may be more favorable at low solute concentration. Furthermore, the values of $k_{2}$ for $\mathrm{As}(\mathrm{III})$ adsorption are higher than those for $\mathrm{As}(\mathrm{V})$ adsorption. This suggests that the removal of $\mathrm{As}(\mathrm{III})$ is faster than that of $\mathrm{As}(\mathrm{V})$. Similar results are observed for adsorption of $\mathrm{As}(\mathrm{V})$ and $\mathrm{As}(\mathrm{III})$ by ferrihydrite [29] 

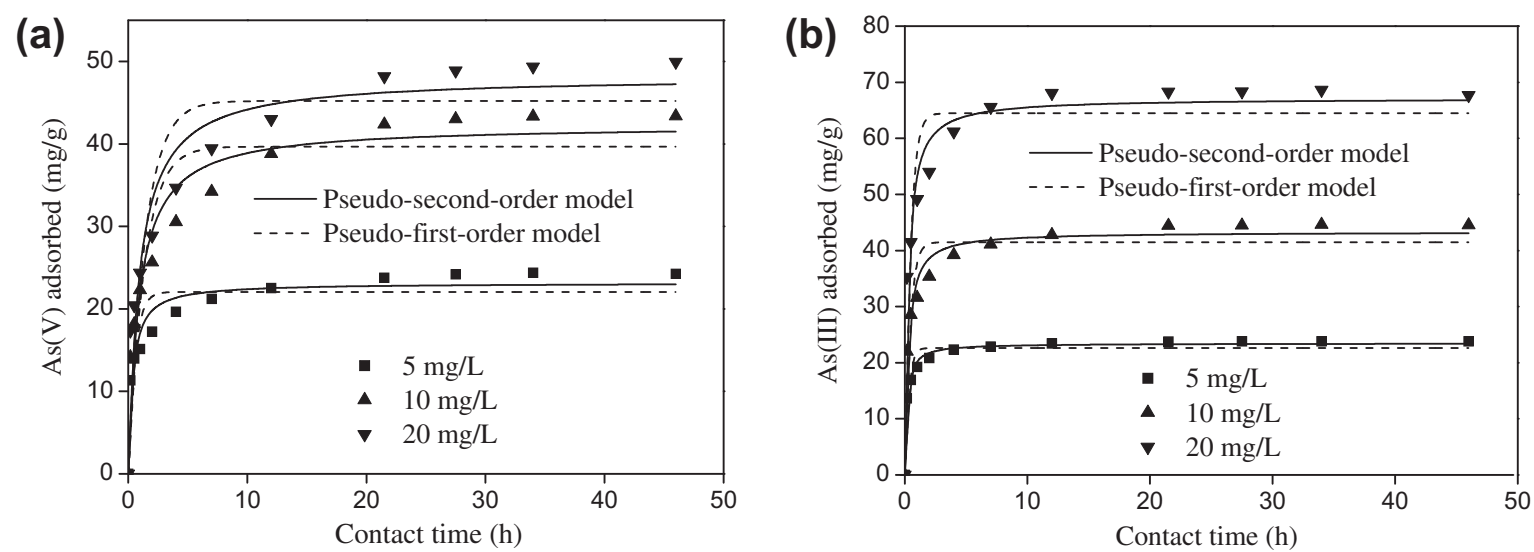

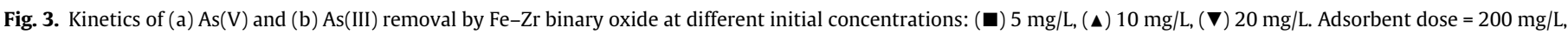
$\mathrm{pH}=7.0 \pm 0.1$, agitation speed $=130 \mathrm{rpm}, T=25 \pm 1{ }^{\circ} \mathrm{C}$.

Table 1

Adsorption rate constant obtained from pseudo-first-order model and pseudosecond-order model for various initial concentrations of arsenic.

\begin{tabular}{|c|c|c|c|c|c|c|c|}
\hline \multirow[t]{2}{*}{$\begin{array}{l}\text { Arsenic } \\
\text { species }\end{array}$} & \multirow{2}{*}{$\begin{array}{l}\text { Initial } \\
\text { concentration } \\
(\mathrm{mg} / \mathrm{L})\end{array}$} & \multicolumn{3}{|c|}{$\begin{array}{l}\text { Pseudo-first-order } \\
\text { model }\end{array}$} & \multicolumn{3}{|c|}{$\begin{array}{l}\text { Pseudo-second-order } \\
\text { model }\end{array}$} \\
\hline & & $\begin{array}{l}k_{1} \\
\left(\mathrm{~h}^{-1}\right)\end{array}$ & $\begin{array}{l}q_{e} \\
(\mathrm{mg} / \mathrm{g})\end{array}$ & $R^{2}$ & $\begin{array}{l}k_{2} \\
(\mathrm{~g} / \mathrm{mg} \mathrm{h})\end{array}$ & $\begin{array}{l}q_{e} \\
(\mathrm{mg} / \mathrm{g})\end{array}$ & $R^{2}$ \\
\hline \multirow[t]{3}{*}{$\operatorname{As}(\mathrm{V})$} & 5 & 1.892 & 22.1 & 0.838 & 0.129 & 23.1 & 0.933 \\
\hline & 10 & 0.758 & 39.7 & 0.858 & 0.027 & 42.3 & 0.938 \\
\hline & 20 & 0.720 & 45.2 & 0.845 & 0.023 & 48.3 & 0.927 \\
\hline \multirow[t]{3}{*}{$\mathrm{As}(\mathrm{III})$} & 5 & 3.958 & 22.6 & 0.933 & 0.294 & 23.8 & 0.987 \\
\hline & 10 & 2.614 & 41.5 & 0.895 & 0.096 & 43.3 & 0.969 \\
\hline & 20 & 2.402 & 64.5 & 0.886 & 0.060 & 67.1 & 0.963 \\
\hline
\end{tabular}

or nanocrystalline titanium dioxide [30]. The kinetics experiments presented in Fig. 4 were carried out at $\mathrm{pH} 7.0 \pm 0.1$. At this $\mathrm{pH}$, the surface potential of $\mathrm{Fe}-\mathrm{Zr}$ binary oxide is negative (see Section 3.7). $\mathrm{As}(\mathrm{V})$ is largely present as negatively charged $\mathrm{H}_{2} \mathrm{AsO}_{4}^{-}$and $\mathrm{HAsO}_{4}^{2-}$ species, while $\mathrm{As}(\mathrm{III})$ is present at neutral $\mathrm{H}_{3} \mathrm{AsO}_{3}$ species. The higher adsorption rate of $\mathrm{As}(\mathrm{III})$ than of $\mathrm{As}(\mathrm{V})$ could be attributed to the lower electrostatic repulsion between the surface and the As(III) species.

A multiexponential equation was also used to fit the kinetic data, and the results and detailed discussion are shown in the Supplementary materials.

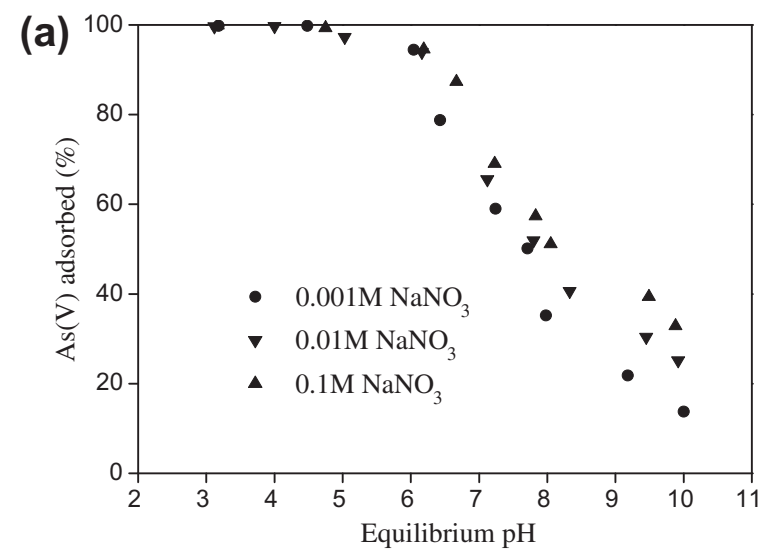

\subsection{Effect of $\mathrm{pH}$ and ionic strength}

The effects of $\mathrm{pH}$ and ionic strength on the removal of $\mathrm{As}(\mathrm{V})$ and As(III) were studied. As can be seen from Fig. 4a, As(V) adsorption is evidently dependent on $\mathrm{pH}$, with the greatest adsorption occurring under acidic conditions, and decreases with an increase in solution $\mathrm{pH}$. Adsorption of strong acid anions by metal oxides and hydroxides typically decreases with increasing $\mathrm{pH}$ [31]. Such a $\mathrm{pH}$ effect was observed for the sorption of $\mathrm{As}(\mathrm{V})$ onto iron oxides or iron-containing oxides [32,33]. $\mathrm{H}_{2} \mathrm{AsO}_{4}^{-}$and $\mathrm{HAsO}_{4}^{2-}$ are dominant $\mathrm{As}(\mathrm{V})$ species in the solution in the tested $\mathrm{pH}$ range $(3-10)$. Lower $\mathrm{pH}$ is favorable for the protonation of the sorbent surface. Increased protonation is thought to increase the positively charged sites, enlarge the attraction force existing between the sorbent surface and arsenate anions, and therefore increase the amount of adsorption in the lower $\mathrm{pH}$ region. With the increase in solution $\mathrm{pH}$, the negatively charged sites gradually dominate, the repulsion effect is enhanced, and the amount of adsorption consequently falls.

In contrast, As(III) adsorption gradually increases with increasing solution $\mathrm{pH}$ and reaches a maximum at $\mathrm{pH}$ approximately 9.0 (Fig. 4b). Adsorption of weak acids by metal oxides usually reaches a maximum at $\mathrm{pH}$ values similar to the $\mathrm{p} k_{\mathrm{a} 1}$ of the acid [31]. The $\mathrm{p} k_{\mathrm{a} 1}$ of arsenious acid is 9.2. The decrease in As(III) sorption at pH over 9.0 may be due to the coulombic repulsion between As(III)

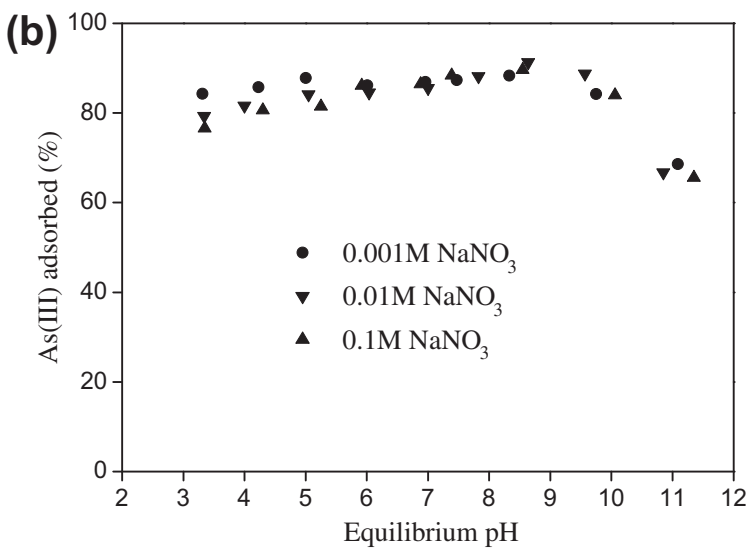

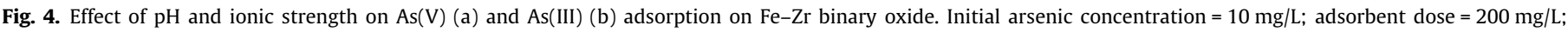
agitation speed $=140 \mathrm{rpm}, T=25 \pm 1{ }^{\circ} \mathrm{C}$. 
species and the negative surfaces of the Fe- $\mathrm{Zr}$ binary oxide $\left(\mathrm{pH}_{\text {ipe }}=5.1\right)$.

Anions that are adsorbed through outer-sphere association are strongly sensitive to ionic strength; the adsorption is suppressed by competition with weakly adsorbing anions such as $\mathrm{NO}_{3}^{-}$, since electrolytes also form outer-sphere complexes through electrostatic forces. Conversely, anions that are adsorbed by the innersphere association either show little sensitivity to ionic strength or respond to higher ionic strength with greater adsorption [34]. For $\mathrm{As}(\mathrm{V})$, the increase in ionic strength from 0.001 to $0.1 \mathrm{M}$ leads to a shift in the position of the $\mathrm{pH}$ edge toward the alkaline region (Fig. 4a), and slightly enhances adsorption in this range (7-10). These behaviors are indicative of an inner-sphere adsorption mechanism for $\mathrm{As}(\mathrm{V})$ on the $\mathrm{Fe}-\mathrm{Zr}$ binary oxide. A similar phenomenon was observed by Deliyanni and co-workers [35] when they studied the adsorption of $\mathrm{As}(\mathrm{V})$ on akaganéite.

For As(III), the change in ionic strength does not significantly influence its sorption on the Fe- $\mathrm{Zr}$ binary oxide above $\mathrm{pH}$ 6. This suggests an inner-sphere adsorption mechanism involved in the sorption. However, As(III) adsorption below pH 6 decreased with increasing ionic strength, suggesting an outer-sphere adsorption mechanism.

\subsection{Adsorption isotherms}

Adsorption isotherms for both $\mathrm{As}(\mathrm{III})$ and $\mathrm{As}(\mathrm{V})$ were obtained at $7.0 \pm 0.1$ by varying the initial arsenic concentrations (5$50 \mathrm{mg} / \mathrm{L}$ ). The isotherms thus obtained are presented in Fig. 5. Obviously, the adsorbent has a much higher adsorption capacity for $\mathrm{As}(\mathrm{III})$ than that of $\mathrm{As}(\mathrm{V})$. Both Langmuir and Freundlich models $[36,37]$ were employed to describe the adsorption isotherms obtained in the figure. The Freundlich equation is represented as

$q_{e}=K_{F} C_{e}^{n}$,

where $q_{e}$ is the amount of arsenic adsorbed onto the solid phase $(\mathrm{mg} / \mathrm{g}), C_{e}$ is the equilibrium arsenic concentration in the solution phase $(\mathrm{mg} / \mathrm{L}), K_{F}$ is roughly an indicator of the adsorption capacity, and $n$ is the heterogeneity factor, which has a lower value for more heterogeneous surfaces.

The Langmuir equation can be written in the form

$q_{e}=\frac{q_{\max } b C_{e}}{1+b C_{e}}$,

where $q_{e}$ and $C_{e}$ are as previously denoted, $b$ is the equilibrium adsorption constant related to the affinity of binding sites $(\mathrm{L} / \mathrm{mg})$,

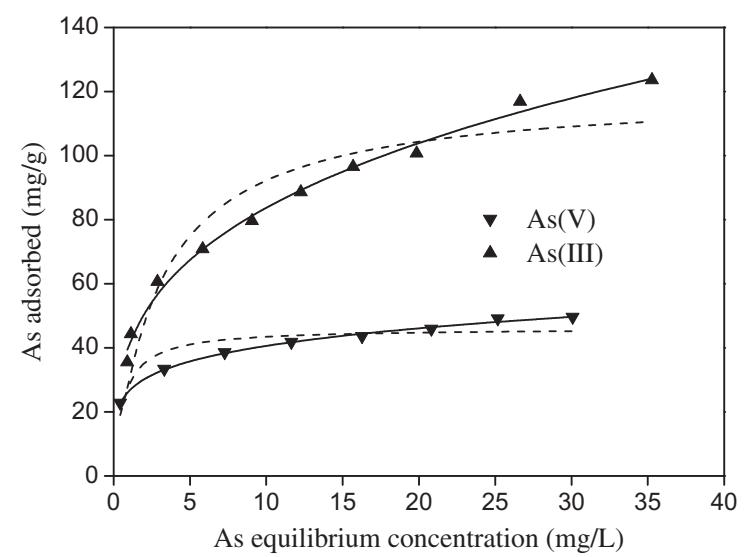

Fig. 5. Isotherms for $\mathrm{As}(\mathrm{III})$ and $\mathrm{As}(\mathrm{V})$ adsorption by Fe-Zr binary oxide at $\mathrm{pH}$ $7.0 \pm 0.1$ and $T=25 \pm 1{ }^{\circ} \mathrm{C}$; (-) Langmuir model and (-) Freundlich model. and $q_{\max }$ is the maximum amount of the arsenic per unit weight of adsorbent for complete monolayer coverage.

The adsorption constants obtained from the isotherms are listed in Table 2. It is seen that the Freundlich model fits the experimental data reasonably well. The Langmuir model is, however, unsuitable for describing the adsorption of arsenic by Fe-Zr binary oxide, due to a relatively poor correlation coefficient $\left(R^{2}<0.90\right)$. The Langmuir isotherm fails to describe the adsorption behavior because it assumes that adsorption occurs on a homogeneous surface. The presence of zirconium dioxide in the adsorbent may lead to a more heterogeneous surface. The Freundlich equation describes adsorption where the adsorbent has a heterogeneous surface with adsorption sites that have different energies of adsorption. The calculated Langmuir adsorption capacities for $\mathrm{As}(\mathrm{V})$ and $\mathrm{As}(\mathrm{III})$ are 46.1 and $120.0 \mathrm{mg} / \mathrm{g}$, respectively. This suggested that Fe-Zr adsorbent is effective for both $\mathrm{As}(\mathrm{V})$ and $\mathrm{As}(\mathrm{III})$ removal, particularly the latter. To assess the arsenic removal performance of Fe- $\mathrm{Zr}$ binary oxide, the $q_{\max }$ values are compared with the reported values (Table 3 ). It is found that the prepared Fe-Zr binary oxide outperforms many other adsorbents. Especially, the values of maximal adsorption capacities of $\mathrm{As}(\mathrm{V})$ and $\mathrm{As}(\mathrm{III})$ obtained in the present study are nearly four times and one time higher than the nano-Fe(III)$\mathrm{Zr}(\mathrm{IV})$ mixed oxide [22,23].

\subsection{Effect of coexisting anions}

Anions such as sulfate, bicarbonate, silicate, and phosphate are generally present in water, and could interfere in the uptake of arsenic through competitive adsorption. Thus, the influences of these anions at three concentration levels $(0.1,1.0$, and $10 \mathrm{mM})$ on the arsenic removal were assessed at $\mathrm{pH} 7.0 \pm 0.1$. The experimental results are presented in Fig. 6.

It is clear that the coexisting sulfate had no significant influence on the $\mathrm{As}(\mathrm{V})$ removal. Only a $5 \%$ reduction in $\mathrm{As}(\mathrm{V})$ removal rate is observed even when the sulfate concentration is as high as $10 \mathrm{mM}$.

Table 2

Langmuir and Freundlich isotherm parameters for $\mathrm{As}(\mathrm{V})$ and $\mathrm{As}(\mathrm{III})$ adsorption onto Fe-Zr binary oxide at $\mathrm{pH} 7.0 \pm 0.1$.

\begin{tabular}{lclllllll}
\hline \multirow{2}{*}{ As species } & \multicolumn{2}{l}{ Langmuir model } & & \multicolumn{3}{l}{ Freundlich model } \\
\cline { 2 - 3 } \cline { 7 - 8 } & $q_{m}(\mathrm{mg} / \mathrm{g})$ & $K_{L}(\mathrm{~L} / \mathrm{mg})$ & $R^{2}$ & & $K_{F}(\mathrm{mg} / \mathrm{g})$ & $n$ & $R^{2}$ \\
\hline $\operatorname{As}(\mathrm{V})$ & 46.1 & 1.611 & 0.788 & & 26.6 & 0.183 & 0.996 \\
$\operatorname{As}(\mathrm{III})$ & 120.0 & 0.332 & 0.894 & & 40.8 & 0.311 & 0.992 \\
\hline
\end{tabular}

Table 3

Comparison of maximum arsenic adsorption capacities for different adsorbents. ${ }^{\text {a }}$

\begin{tabular}{|c|c|c|c|c|}
\hline Adsorbent & $\begin{array}{l}\text { Conc. } \\
\text { range } \\
(\mathrm{mg} / \mathrm{L})\end{array}$ & $\begin{array}{l}\text { Max. As(III) } \\
\text { adsorption } \\
\text { capacity }(\mathrm{mg} / \mathrm{g})\end{array}$ & $\begin{array}{l}\text { Max. As(V) } \\
\text { adsorption } \\
\text { capacity (mg/g) }\end{array}$ & Ref. \\
\hline Fe-Zr binary oxide & $5-40$ & $120.0(\mathrm{pH} 7.0)$ & $46.1(\mathrm{pH} 7.0)$ & $\begin{array}{l}\text { Present } \\
\text { study }\end{array}$ \\
\hline Fe-Mn binary oxide & $5-40$ & $132.7(\mathrm{pH} \mathrm{5.0})$ & $69.8(\mathrm{pH} \mathrm{5.0)}$ & [19] \\
\hline $\begin{array}{l}\text { Nano-Fe(III)-Ti(IV) } \\
\text { mixed oxide }\end{array}$ & $\begin{array}{l}5.0- \\
250\end{array}$ & $85.0(\mathrm{pH} \mathrm{7.0)}$ & $14.3(\mathrm{pH} 7.0)$ & [20] \\
\hline $\begin{array}{l}\text { Nano-Fe(III)-Zr(IV) } \\
\text { mixed oxide }\end{array}$ & $5-350$ & $\begin{array}{l}64.5-66.5(\mathrm{pH} \\
7.0)\end{array}$ & $9.36(\mathrm{pH} 7.0)$ & {$[22,23]$} \\
\hline Akaganeite nanocrystals & $5-25$ & - & $134.1(\mathrm{pH} 7.5)$ & [35] \\
\hline Nano- $\mathrm{TiO}_{2}$ & & $59.9(\mathrm{pH} 7.0)$ & $37.5(\mathrm{pH} 7.0)$ & [30] \\
\hline $\mathrm{Al}_{2} \mathrm{O}_{3} / \mathrm{Fe}(\mathrm{OH})_{3}$ & $\begin{array}{l}7.5- \\
135\end{array}$ & $9.0(\mathrm{pH} \mathrm{6.6)}$ & $36.7(\mathrm{pH} 7.2)$ & [38] \\
\hline CuO nanoparticle & $\begin{array}{l}0.1- \\
100\end{array}$ & $26.9(\mathrm{pH} 8.0)$ & $22.6(\mathrm{pH} 8.0)$ & [39] \\
\hline $\begin{array}{l}\text { Zr-based magnetic } \\
\text { sorbent }\end{array}$ & $0-100$ & - & $\begin{array}{l}45.6(\mathrm{pH} 5.0- \\
6.0)\end{array}$ & {$[40]$} \\
\hline
\end{tabular}

${ }^{\mathrm{a}} \mathrm{pH}$ is shown in parentheses. 
(a)

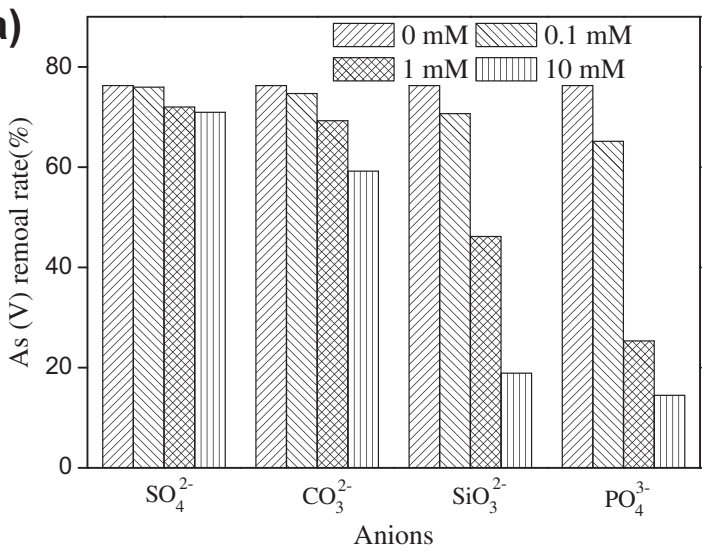

(b)

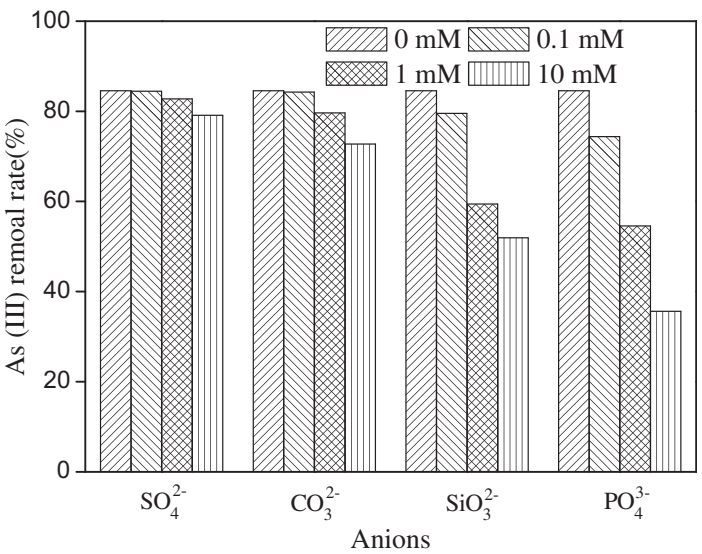

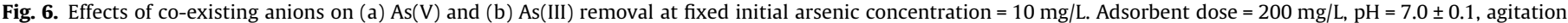
speed $=140 \mathrm{rpm}, T=25 \pm 1{ }^{\circ} \mathrm{C}$.

The presence of bicarbonate slightly decreases the removal of $\operatorname{As}(V)$. However, the coexisting silicate and phosphate greatly hindered the $\mathrm{As}(\mathrm{V})$ adsorption.

The As(III) removal is less affected by these anions than that of $\mathrm{As}(\mathrm{V})$, as shown in Fig. 6b. Among the anions, phosphate causes the greatest decrease in arsenic adsorption, which may be due to the strong competition for the binding sites of the adsorbent between the phosphate and arsenic. Both phosphate and arsenic are located in the same main group, and the molecular structure of the phosphate ion is very similar to that of the arsenic ion. Thus, the present phosphate ions must strongly compete with arsenic ions for adsorptive sites on the surfaces of Fe- $\mathrm{Zr}$ binary oxides.

\subsection{Zeta potential measurement}

The zeta potentials of the Fe-Zr binary oxide suspensions before and after arsenic adsorption were measured. As shown in Fig. 7, the Fe-Zr binary oxide has an isoelectric point of about 5.1, which was decreased to about 4.1 after $\mathrm{As}(\mathrm{V})$ adsorption. However, the isoelectric point is not significantly changed after the As(III) adsorption. The specific adsorption of anions makes the surface of oxides more negatively charged, which results in a shift of the isoelectric point of adsorbent to a lower $\mathrm{pH}$ value $[41,42]$.

For $\mathrm{As}(\mathrm{V})$, specific adsorption rather than purely electrostatic interaction is further confirmed from the drop of isoelectric point at the aqueous arsenate/Fe- $\mathrm{Zr}$ binary oxide interface. However, lack of shift in IEP cannot be used to infer an outer-sphere adsorption mechanism, since inner-sphere surface complex formation is not necessarily accompanied by a change in the mineral surface [43]. For As(III), no obvious change in the isoelectric point of the $\mathrm{Fe}-\mathrm{Zr}$ binary oxide is observed after its sorption, which indicates the formation of either an outer-sphere surface complex or an inner-sphere complex that may not change the surface charge.

\subsection{Analysis of XPS and FTIR spectra}

XPS spectra of Fe-Zr binary oxide and samples after arsenic adsorption were collected to verify the presence of arsenic and determine the oxidation state of adsorbed arsenic. Fig. 8 shows the presence of the As3d core level peak as well as the AsLMM and As3p peaks, which clearly indicates the adsorption of $\mathrm{As}(\mathrm{V})$ and $\mathrm{As}(\mathrm{III})$ onto the sorbent.

Fig. 9 exhibits the As3d core level of the Fe-Zr binary oxide after the adsorption of $\mathrm{As}(\mathrm{V})$ and $\mathrm{As}(\mathrm{III})$. The As3d binding energies are 45.5 and $44.4 \mathrm{eV}$, respectively. The values of the binding energy

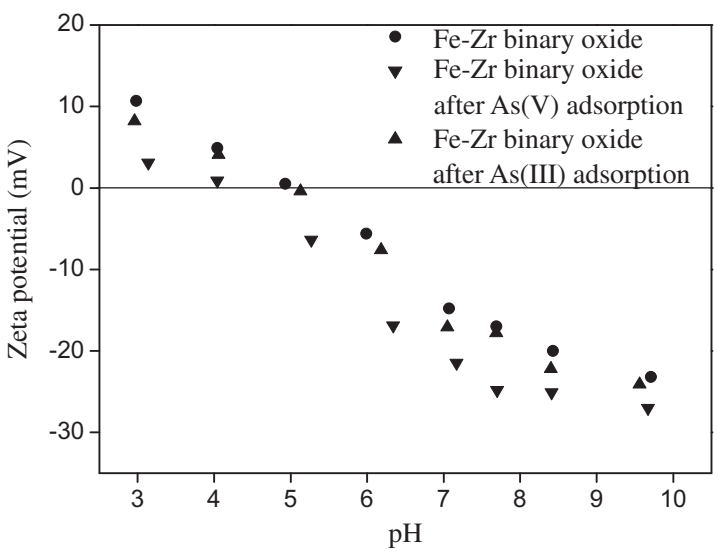

Fig. 7. Zeta potential of Fe-Zr binary oxide before and after arsenic adsorption at initial arsenic concentration $=10 \mathrm{mg} / \mathrm{L}$. Adsorbent dose $=200 \mathrm{mg} / \mathrm{L}$, ionic strength $=0.01 \mathrm{M} \mathrm{NaNO}_{3}$, equilibrium time $=72 \mathrm{~h}$.

of the As3d core level for $\mathrm{As}(\mathrm{III})$ and $\mathrm{As}(\mathrm{V})$ in arsenic oxides are reportedly $44.3-44.5$ and $45.2-45.6 \mathrm{eV}$, respectively [44,45]. They can be shifted up to $44.6 \pm 0.13 \mathrm{eV}$ for $\mathrm{As}$ (III) and $46.0 \pm 0.17 \mathrm{eV}$ for $\mathrm{As}(\mathrm{V})$ when the arsenic anions or molecules are adsorbed onto iron oxide [46]. It can therefore be concluded that the arsenic species adsorbed onto the surface of the $\mathrm{Fe}-\mathrm{Zr}$ oxide after the binding of $\mathrm{As}(\mathrm{V})$ and $\mathrm{As}(\mathrm{III})$ still remain as $\mathrm{As}(\mathrm{V})$ and $\mathrm{As}(\mathrm{III})$, respectively. In other words, the oxidation state of As(III) is not changed during the adsorption process.

More useful information about the interaction between aqueous arsenic and solid Fe-Zr binary oxide can be provided by the FTIR technique. Fig. 10 shows the FTIR spectra in which spectrum (a) is for original Fe-Zr binary oxide, spectrum (b) for Fe-Zr binary oxide treated with $40 \mathrm{mg} / \mathrm{L} \mathrm{As}$ (III) solution at $\mathrm{pH} 7.0$, and spectrum (c) for $\mathrm{Fe}-\mathrm{Zr}$ binary oxide treated with of $\mathrm{Fe}-\mathrm{Zr}$ binary oxide $\mathrm{mg} / \mathrm{L}$ $\mathrm{As}(\mathrm{V})$ solution at $\mathrm{pH}$ 7.0. For the Fe-Zr binary oxide sample, the bands at $3400 \mathrm{~cm}^{-1}$ may be assigned to the vibration of $\mathrm{O}-\mathrm{H}$ stretching and $1630 \mathrm{~cm}^{-1}$ may be assigned to the deformation vibration of water molecules, indicating the presence of physisorbed water on the oxide. For the $A s(V)$-treated sample, a new peak at $827 \mathrm{~cm}^{-1}$ could be assigned to the vibration (As-OH) of As-O-Fe groups [43]. This indicates that the $\mathrm{As}(\mathrm{V})$ is mainly bound as a surface complex. However, no obvious change can be observed in the spectrum of the As(III)-loaded adsorbent. In fact, in contrast to the spectra of $\mathrm{As}(\mathrm{V})$ sorbed into Fe oxides, it is difficult to detect the presence of sorbed As(III) on the surface of Fe oxides [43]. 


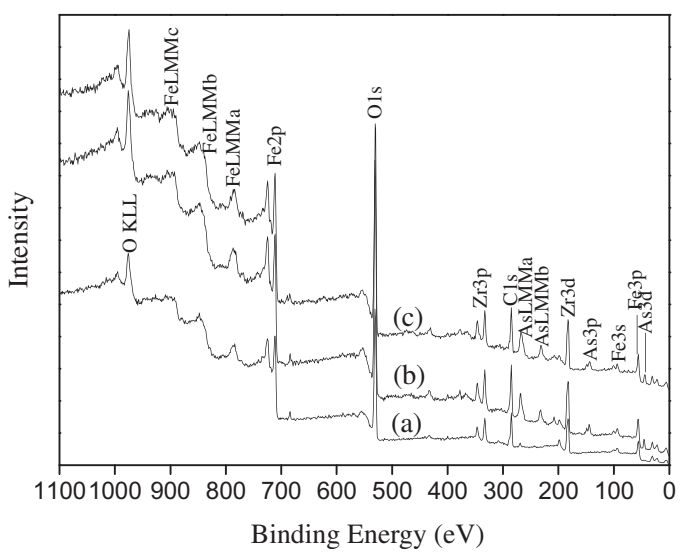

Fig. 8. XPS spectra of Fe-Zr binary oxide (a) as prepared; (b) after reaction with $\mathrm{As}(\mathrm{V})$; and (c) after reaction with As(III).

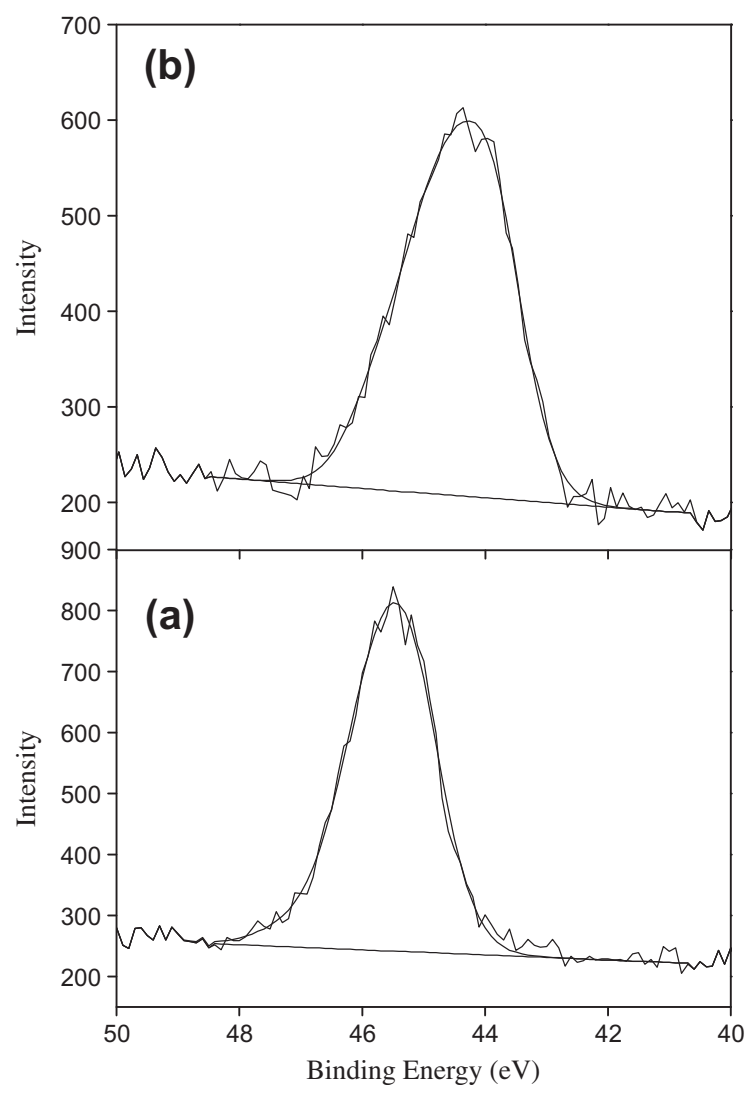

Fig. 9. As3d core level of the Fe-Zr binary oxide (a) after reaction with $\mathrm{As}(\mathrm{V})$ and (b) after reaction with $\mathrm{As}(\mathrm{III})$.

From the results of the ionic strength effects experiment and the analyses of zeta potential along with FTIR spectra, reasonable mechanisms for arsenic adsorption on the Fe-Zr binary oxide can be provided. $\mathrm{As}(\mathrm{V})$ is adsorbed by formation of inner-sphere surface complexes, while As(III) is adsorbed by formation of both inner- and outer-sphere surface complexes. Fig. 11 demonstrates the proposed mechanisms.

\section{Conclusions}

The preparation of $\mathrm{Fe}-\mathrm{Zr}$ binary oxide is a simple and environmentally friendly method. This adsorbent, with a high surface area

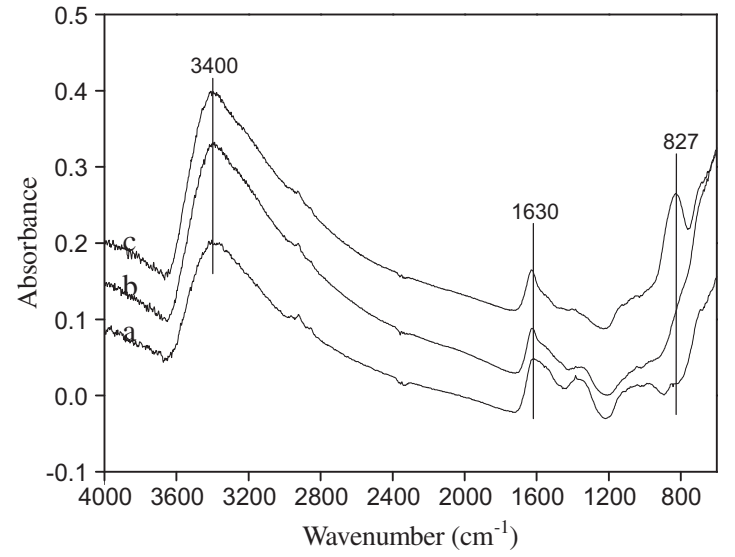

Fig. 10. FTIR spectra of Fe-Zr binary oxide (a), after treatment with As(III) solution of $40 \mathrm{mg} / \mathrm{L}$ (b), and after treatment with $\mathrm{As}(\mathrm{V})$ solution of $40 \mathrm{mg} / \mathrm{L}$ (c).
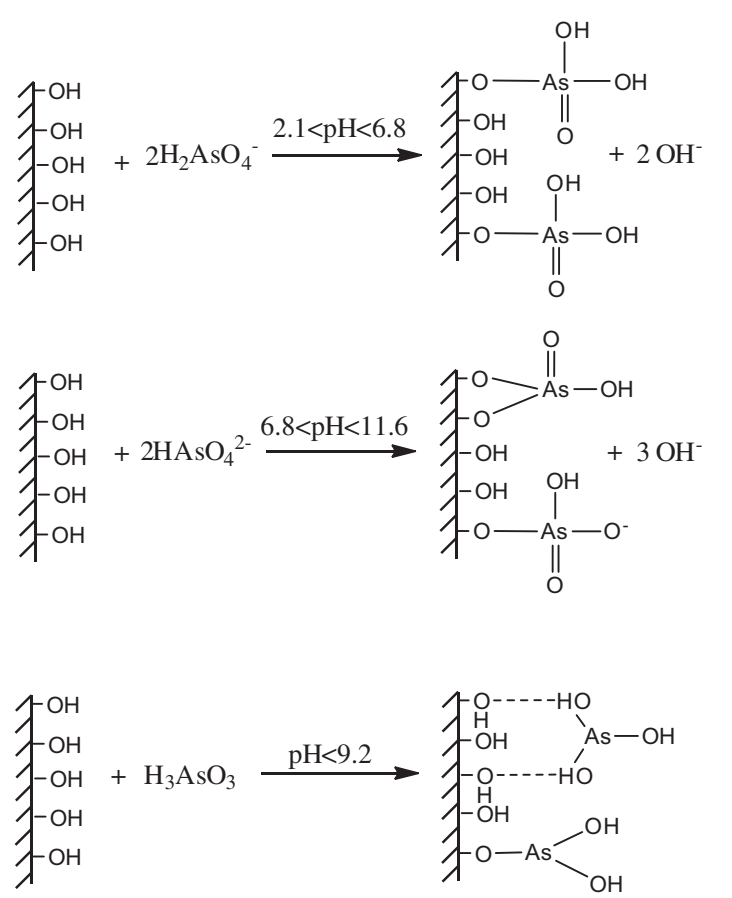

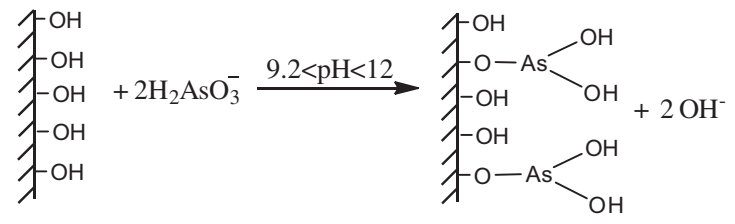

Fig. 11. Schematic diagram of adsorption mechanisms of $\mathrm{As}(\mathrm{V})$ (a) and $\mathrm{As}(\mathrm{III})$ (b).

(339 $\mathrm{m}^{2} / \mathrm{g}$ ), was amorphous. The pseudo-second-order equation describes the kinetic data well. The adsorbent had a high removal capacity toward both $\mathrm{As}(\mathrm{V})$ and $\mathrm{As}(\mathrm{III})$. Maximal adsorption capacities were $46.1 \mathrm{mg} / \mathrm{g}$ and $120.0 \mathrm{mg} / \mathrm{g}$ at $\mathrm{pH} 7.0$, respectively. The $\mathrm{Fe}-\mathrm{Zr}$ binary oxide is able to adsorb arsenic in the presence of competing anions and across a wide range of $\mathrm{pH}$. Among the coexisting anions, phosphate was the greatest competitor with arsenic for adsorptive sites on the surface of oxide. The results of ionic strength effects experiment and analyses of zeta potential and FTIR 
spectra indicate that $\mathrm{As}(\mathrm{V})$ forms inner-sphere surface complexes, while As(III) forms both inner- and outer-sphere surface complexes at the water/Fe-Zr binary oxide interface.

\section{Acknowledgments}

This research was financially supported by the National Natural Science Foundation of China (Grant No. 20807035 and 50728806), the Innovative Program of the Chinese Academy of Sciences (KZCX2-YW-Q07-04) and Agency for Science, technology and Research (A*Star) of Singapore (R-288-000-066-305, 092101 0059).

\section{Appendix A. Supplementary material}

Supplementary data associated with this article can be found, in the online version, at doi:10.1016/j.jcis.2011.01.013.

\section{References}

[1] C.K. Jain, I. Ali, Water Res. 34 (2000) 4304-4312.

[2] B.K. Mandal, K.T. Suzuki, Talanta 58 (2002) 201-235.

[3] L.C. Roberts, S.J. Hug, T. Ruettimann, A.W. Khan, M.T. Rahman, Environ. Sci. Technol. 38 (2004) 307-315.

[4] T.R. Holm, J. Am, Water Works Assoc. 94 (2002) 174-181.

[5] J.F. Ferguson, J. Gavis, Water Res. 6 (1972) 1259-1274.

[6] J.G. Hering, P.Y. Chen, J.A. Wilkie, M. Elimelech, J. Environ. Eng. 133 (1997) $103-111$.

[7] K.N. Scott, J.F. Green, H.D. Do, S.J. Mclean, J. AWWA 87 (1995) 114-126.

[8] E.O. Kartinen Jr., C.J. Martin, Desalination 103 (1995) 79-88.

[9] J.A. Wilkie, J.G. Hering, Colloids Surf., A 107 (1996) 97-110.

[10] M. Jang, S.H. Min, T.H. Kim, J.K. Park, Environ. Sci. Technol. 40 (2006) 16361643.

[11] J.J. Waypa, M. Elimelech, J.G. Hering, J. AWWA 89 (1997) 102-116.

[12] W. Driehaus, M. Jekel, U. Hildebrandt, J. Water SRT-Aqua. 47 (1998) 1-6.

[13] A. Maiti, S. DasGupta, J.K. Basu, S. De, Sep. Sci. Technol. 55 (2007) 350-359.

[14] W. Driehaus, R. Seith, M. Jekel, Water Res. 29 (1994) 297-305.

[15] T.S. Singh, K.K. Pant, Sep. Sci. Technol. 36 (2004) 139-147.

[16] S. Dixit, J.G. Hering, Environ. Sci. Technol. 37 (2003) 4182-4189.

[17] M.L. Pierce, C.B. Moore, Water Res. 16 (1982) 1247-1253.
[18] Y. Zhang, M. Yang, X.M. Dou, H. He, D.S. Wang, Environ. Sci. Technol. 39 (2005) $7246-7253$.

[19] G.S. Zhang, J.H. Qu, H.J. Liu, R.P. Liu, R.C. Wu, Water Res. 41 (2007) 1921-1928.

[20] K. Gupta, U.C. Ghosh, J. Hazard. Mater. 161 (2009) 884-892.

[21] N. Seko, F. Basuki, M. Tamada, F. Yoshii, React. Funct. Polym. 59 (2004) 235241.

[22] K. Gupta, K. Biswas, U.C. Ghosh, Ind. Eng. Chem. Res. 47 (2008) 9903-9912.

[23] K. Gupta, T. Basu, U.C. Ghosh, J. Chem. Eng. Data 54 (2009) 2222-2228.

[24] U. Schwertmann, R.M. Cornell, Iron Oxides in the Laboratory: Preparation and Characterization, second ed., Wiley-VCH, Weinheim, 2000.

[25] A. Hofmann, M. Pelletier, L. Michot, A. Stradner, P. Schurtenberger, R. Kretzschmar, J. Colloid Interface Sci. 271 (2004) 163-173.

[26] US Environmental Protection Agency (online). Drinking Water Contaminants. <http://water.epa.gov/drink/contaminants/index.cfm>.

[27] S. Lagergren, Handlingar, Band 24 (4) (1898) 1-39.

[28] Y.S. Ho, G. McKay, Adsorpt. Sci. Technol. 16 (1998) 243-255.

[29] K.P. Raven, A. Jain, R.H. Loeppert, Environ. Sci. Technol. 32 (1998) 344-349.

[30] M.E. Pena, G.P. Korfiatis, M. Patel, L. Lippicott, X.G. Meng, Water Res. 39 (2005) 2327-2337.

[31] W. Stumm, Chemistry of the Solid-Water Interface, Wiley-Interscience, New York, 1996.

[32] F.J. Hingston, A.M. Posner, J.P. Quirk, J. Soil Sci. 23 (1972) 177-192.

[33] G.S. Zhang, H.J. Liu, R.P. Liu, J.H. Qu, J. Colloid Interface Sci. 335 (2009) 168174.

[34] M.B. McBride, Clays Clay Miner. 45 (1997) 598-608.

[35] E.A. Deliyanni, D.N. Bakoyannakis, A.I. Zouboulis, K.A. Matis, Chemosphere 50 (2003) 155-163.

[36] I. Langmuir, J. Am. Chem. Soc. 38 (1916) 2221-2295.

[37] H.M.F. Freundlich, Z. Phys. Chem. A 57 (1906) 385-470.

[38] J. Hlavay, K. Polyák, J. Colloid Interface Sci. 284 (2005) 71-77.

[39] C.A. Martinson, K.J. Reddy, J. Colloid Interface Sci. 336 (2009) 406-411.

[40] Y.M. Zheng, S.F. Lim, J.P. Chen, J. Colloid Interface Sci. 338 (2009) 22-29.

[41] W. Stumm, J.J. Morgan, Aquatic Chemistry: Chemical Equilibria and Rates in Natural Waters, third ed., John-Wiley and Sons, New York, 1996.

[42] T.H. Hsia, S.L. Lo, C.F. Lin, D.Y. Lee, Colloids Surf., A 85 (1994) 1-7.

[43] S. Goldberg, C.T. Johnston, J. Colloid Interface Sci. 234 (2001) 204-216.

[44] H.W. Nesbitt, G.W. Canning, G.M. Bancroft, Geochim. Cosmochim. Acta 62 (1998) 2097-2110.

[45] S. Ouvrard, P. Donato, M.O. Simonnot, S. Begin, J. Ghanbaja, M. Alnot, Y.B. Duval, F. Lhote, O. Barres, M. Sardin, Geochim. Cosmochim. Acta 69 (2005) 2715-2724.

[46] M. Ding, B.H.W.S.D. de Jong, S.J. Roosendall, A. Vredenberg, Geochim. Cosmochim. Acta 64 (2000) 1209-1219. 